\title{
On Some Fundamental Integrodifferential Inequalities
}

\author{
Zareen A. Khan \\ Department of Mathematics, Princess Noura Bint Abdurehman University, Riyadh, KSA \\ Email: dr.zareenkhan@ymail.com
}

Received 6 September 2014; revised 8 October 2014; accepted 18 October 2014

Copyright (C) 2014 by author and Scientific Research Publishing Inc.

This work is licensed under the Creative Commons Attribution International License (CC BY). http://creativecommons.org/licenses/by/4.0/

c) (i) Open Access

\section{Abstract}

The aim of this present paper is to establish some new integrodifferential inequalities of Gronwall type involving functions of one independent variable which provide explicit bounds on unknown functions. The inequalities given here can be used in the analysis of a class of differential equations as handy tools.

\section{Keywords}

\section{Integral Inequalities, Two Independent Variables, Nondecreasing, Nonincreasing}

\section{Introduction}

The differential and integral inequalities occupy a very privileged position in the theory of differential and integral equations. In recent years, these inequalities have been greatly enriched by the recognition of their potential and intrinsic worth in many applications of the applied sciences. The integrodifferential inequalities recently established by Gronwall and others [1]-[12] have attracted considerable attention in the theory of differential and integral equations. This fact encourages us to find the explicit bounds on some fundamental integrodifferential inequalities which can be applied fairly well to achieve a diversity of desired goals. In [3], Pachpatte (1977) gave the following useful integrodifferential inequality:

Let $u(t), \dot{u}(t)$ and $b(t)$ be nonnegative continuous functions defined on $R_{+}$and $a>0$ is constant. If

$$
\dot{u}(t) \leq a+\int_{0}^{t} u(s) \dot{u}(s)(u(s)+\dot{u}(s)) \mathrm{d} s
$$

for $t \in R_{+}$and $E(t)$ is defined by

$$
E(t)=1-[a+u(0)] \int_{0}^{t} \mathrm{e}^{\alpha} b(\sigma) \mathrm{d} \sigma
$$


then

$$
\dot{u}(t) \leq a \exp \left([a+u(0)] \int_{0}^{t} \mathrm{e}^{s} b(s)(E(s))^{-1} \mathrm{~d} s\right)
$$

for $t \in[0, \beta)$ where

$$
\beta=\sup \left\{t \in R_{+}: E(t)>0\right\} \text {. }
$$

Our goal in this paper is to establish new explicit bounds on some basic integrodifferential inequalities of one independent variable which will be equally important in handling the inequality (1.1). Given application in this paper also illustrates the usefulness of our result.

\section{Main Results}

Theorem 2.1: Let $u(t), \dot{u}(t)$ and $k(t)$ be nonnegative continuous functions defined on $I=[0, \infty)$ for which the inequality

$$
\dot{u}(t) \leq c+\int_{0}^{t} k(s) \dot{u}(s)\left(\dot{u}^{p}(s)+u^{2}(s)\right) \mathrm{d} s, \quad t \in I
$$

holds, where $c$ is positive constant and $p \geq 1$. If

$$
1-p^{2}(2 p-1)\left[c^{p^{2}}+u(0)+u^{2 p}(0)\right]^{2 p-1} \int_{0}^{t} k(s) \mathrm{e}^{(2 p-1) s} \mathrm{~d} s>0, \quad t \in I
$$

and

$$
1-\left[c^{p^{2}}+u^{2}(0)\right]^{p} \int_{0}^{t}\left(p^{2} k(s)-2 p\right) \exp \left(2 p \int_{0}^{s} Q_{1}(r) \mathrm{d} r\right) \mathrm{d} s>0, \quad t \in I
$$

then

$$
\dot{u}(t) \leq \exp \left[\int_{0}^{t} k(s) R_{1}(s) \mathrm{d} s\right],
$$

$\forall t \in I$, and

$$
R_{1}(t)=\frac{\left[c^{p}+u^{2}(0)\right] \exp \left(2 p \int_{0}^{t} Q_{1}(s) \mathrm{d} s\right)^{\frac{1}{p}}}{\left[1-\left[c^{p}+u^{2}(0)\right]^{p} \int_{0}^{t}\left(p^{2} k(s)-2 p\right) \exp \left(2 p \int_{0}^{s} Q_{1}(r) \mathrm{d} r\right) \mathrm{d} s\right]^{\frac{1}{p}}}
$$

also

$$
Q_{1}(t)=\frac{\left[c^{p^{2}}+u^{2 p}(0)+u(0)\right] \mathrm{e}^{t}}{\left[1-p^{2}(2 p-1)\left[c^{p^{2}}+u^{2 p}(0)+u(0)\right]^{2 p-1} \int_{0}^{y} k(s) \mathrm{e}^{(2 p-1)} \mathrm{d} s\right]^{\frac{1}{2 p-1}}}
$$

Proof: Define a function $m(t)$ by the right-hand side of (2.1). Then

$$
m(t)=c+\int_{0}^{t} k(s) \dot{u}(s)\left(\dot{u}^{p}(s)+u^{2}(s)\right) \mathrm{d} s
$$

where

$$
m(0)=c
$$


Then from (2.1) and (2.7), we have

$$
\dot{u}(t) \leq m(t)
$$

Integrating both sides of (2.9) from 0 to $t$, we observe that

$$
u(t) \leq u(0)+\int_{0}^{t} m(s) \mathrm{d} s
$$

Differentiating both sides of (2.7) with respect to $t$ and using (2.9) and (2.10), we get

$$
\dot{m}(t) \leq k(t) m(t)\left[m^{p}(t)+\left[u(0)+\int_{0}^{t} m(s) \mathrm{d} s\right]^{2}\right]
$$

Define a function $n(t)$ by the right-hand side of (2.11), then

$$
n(t)=m^{p}(t)+\left[u(0)+\int_{0}^{t} m(s) \mathrm{d} s\right]^{2}
$$

where

$$
n(0)=c^{p}+u^{2}(0)
$$

It is clear that

$$
m(t) \leq n(t)
$$

By using (2.12) in (2.11), we have

$$
\dot{m}(t) \leq k(t) m(t) n(t)
$$

Differentiating both sides of (2.12) with respect to $t$, we get

$$
\dot{n}(t)=p m^{p-1}(t) \dot{m}(t)+2\left[u(0)+\int_{0}^{t} m(s) \mathrm{d} s\right] m(t)
$$

By using (2.14) and (2.15) in the above equation, we observe that

$$
\dot{n}(t) \leq n^{p+1}(t)[p k(t)-2]+2 n(t)\left[n^{p}(t)+u(0)+\int_{0}^{t} n(s) \mathrm{d} s\right]
$$

Let

$$
z(t)=n^{p}(t)+u(0)+\int_{0}^{t} n(s) \mathrm{d} s
$$

where

$$
z(0)=n^{p}(0)+u(0)=\left[c^{p}+u^{2}(0)\right]^{p}+u(0)
$$

and

$$
n(t) \leq z(t)
$$

Using (2.17) in (2.16), we get

$$
\dot{n}(t) \leq n^{p+1}(t)[p k(t)-2]+2 n(t) z(t)
$$

Differentiating both sides of (2.17) with respect to $t$, we get

$$
\dot{z}(t)=p n^{p-1}(t) \dot{n}(t)+n(t)
$$

Inequality (2.21) by using (2.19) and (2.20), and since $z^{p+1}(t) \leq z^{2 p}(t)$ if $p \geq 1$ takes the form 


$$
z^{-2 p}(t) \dot{z}(t)-z^{-2 p+1}(t) \leq p^{2} k(t)
$$

Let

$$
r(t)=z^{-2 p+1}(t)
$$

where

$$
r(0)=z^{-2 p+1}(0)=\left[\left[c^{p}+u^{2}(0)\right]^{p}+u(0)\right]^{-2 p+1}
$$

Differentiating both sides of (2.23) with respect to $t$, we get

$$
\dot{r}(t)=(-2 p+1) z^{-2 p}(t) \dot{z}(t)
$$

Inequality (2.22) by using (2.23) and (2.25), takes the form

$$
\dot{r}(t)+(2 p-1) r(t) \geq-p^{2}(2 p-1) k(t)
$$

Multiplying both sides of (2.26) by $e^{(2 p-1) t}$ and integrating the resulting inequality from 0 to $t$, and using (2.24), we have

$$
r(t) \geq\left[c^{p^{2}}+u^{2 p}(0)+u(0)\right]^{-(2 p-1)} \mathrm{e}^{-(2 p-1) t}-p^{2}(2 p-1) \mathrm{e}^{-(2 p-1) t} \int_{0}^{t} k(s) \mathrm{e}^{(2 p-1) s} \mathrm{~d} s
$$

By using (2.23) in the above inequality, it can be seen that

$$
\begin{aligned}
z(t) \leq & {\left[\left[c^{p^{2}}+u^{2 p}(0)+u(0)\right]^{-(2 p-1)} \mathrm{e}^{-(2 p-1) t}\right]^{-\frac{1}{2 p-1}} } \\
& \times\left[1-p^{2}(2 p-1) \mathrm{e}^{-(2 p-1) t}\left[c^{p^{2}}+u^{2 p}(0)+u(0)\right]^{2 p-1} \int_{0}^{t} k(s) \mathrm{e}^{(2 p-1)} \mathrm{d} s\right]^{-\frac{1}{2 p-1}} .
\end{aligned}
$$

which can be rewritten as

$$
z(t) \leq \frac{\left[c^{p^{2}}+u^{2 p}(0)+u(0)\right] \mathrm{e}^{t}}{\left[1-p^{2}(2 p-1)\left[c^{p^{2}}+u^{2 p}(0)+u(0)\right]^{2 p-1} \int_{0}^{t}(s) \mathrm{e}^{(2 p-1) s} \mathrm{~d} s\right]^{\frac{1}{2 p-1}}}=Q_{1}(t)
$$

Using (2.27) in (2.20), we observe that

$$
n^{-(p+1)}(t) \dot{n}(t)-2 Q_{1}(t) n^{-p}(t) \leq[p k(t)-2]
$$

Let

$$
h(t)=n^{-p}(t)
$$

where

$$
h(0)=n^{-p}(0)=\left[c^{p}+u^{2}(0)\right]^{-p}
$$

Differentiating both sides of (2.29) with respect to $t$, we get

$$
\dot{h}(t)=-p n^{-p-1}(t) \dot{h}(t)
$$

Inequality (2.28) by using (2.29) and (2.31), takes the form

$$
\dot{h}(t)+2 p Q_{1}(t) h(t) \geq-\left[p^{2} k(t)-2 p\right]
$$


Multiplying both sides of (2.32) by $\exp \left(2 p \int_{0}^{t} Q(T) \mathrm{d} T\right)$ and integrating the resulting inequality from 0 to $t$,
and using (2.29) and (2.30), we have $n^{-p}(t) \geq\left[c^{p}+u^{2}(0)\right]^{-p} \exp \left(-2 p \int_{0}^{t} Q_{1}(s) \mathrm{d} s\right)-\exp \left(-2 p \int_{0}^{t} Q_{1}(s) \mathrm{d} s\right) \times \int_{0}^{t}\left(p^{2} k(s)-2 p\right) \exp \left(2 p \int_{0}^{s} Q_{1}(\alpha) \mathrm{d} \alpha\right) \mathrm{d} t$

which can be rewritten as

$$
n(t) \leq \frac{\left[c^{p}+u^{2}(0)\right] \exp \left(2 p \int_{0}^{t} Q(s) \mathrm{d} s\right)^{\frac{1}{p}}}{\left[1-\left[c^{p}+u^{2}(0)\right]^{p} \int_{0}^{t}\left[p^{2} k(s)-2 p\right] \exp \left(2 p \int Q(\alpha) \mathrm{d} \alpha\right) \mathrm{d} t\right]^{\frac{1}{p}}}=R_{1}(t)
$$

From (2.15) and (2.33), we get

$$
\frac{\dot{m}(t)}{m(t)} \leq k(t) R_{1}(t)
$$

Integrating both sides of the above inequality from 0 to $t$, and from (2.8), we observe that

$$
m(t) \leq \operatorname{cexp}\left[\int_{0}^{t} k(s) R_{1}(s) \mathrm{d} s\right]
$$

From (2.9) and (2.34), we have

$$
\dot{u}(t) \leq \operatorname{cexp}\left[\int_{0}^{t} k(s) R_{1}(s) \mathrm{d} s\right]
$$

Application: As an application we obtain the bound on the solution of the differential equation of the formulation of the form

$$
\ddot{x}(t)=\dot{x}(t) f\left(t, \dot{x}^{p}, x^{2}\right)
$$

with the given initial conditions

$$
\dot{x}(0)=a, \quad x(0)=c
$$

where $f: I \times R \times R \rightarrow R$ is a continuous function and $a, c$ are real constants. $I=\left[t_{0}, \infty\right), t_{0} \geq 0$. Here we assume that the solution $x(t)$ of (2.35) and (2.36) exists on $R_{+}$Assume that the function in (2.35) satisfies the condition

$$
\left|f\left(t, \dot{x}^{2}, x\right)\right| \leq k(t)\left[\left|\dot{x}^{p}\right|+x^{2}\right], \quad \forall t \in I
$$

where $k(t)$ is a real valued nonnegative continuous function defined on $I$. If

$$
1-p^{2}(2 p-1)\left[a^{p^{2}}+c+c^{2 p}\right]^{2 p-1} \int_{0}^{t} k(s) \mathrm{e}^{(2 p-1) s} \mathrm{~d} s>0, \quad t \in I
$$

and

$$
1-\left[a^{p^{2}}+c^{2}\right]^{p} \int_{0}^{t}\left(p^{2} k(s)-2 p\right) \exp \left(2 p \int_{0}^{s} Q_{1}(r) \mathrm{d} r\right) \mathrm{d} s>0, \quad t \in I
$$

then the bounds on the solution (2.35) takes the form

$$
|\dot{x}(t)| \leq a \exp \left(\int_{0}^{t} k(s) R(s) \mathrm{d} s\right)
$$

$\forall t \in I$, where, $p \geq 1$, and 


$$
R(t)=\frac{\left[a^{p}+c^{2}\right] \exp \left(2 p \int_{0}^{t} Q_{1}(s) \mathrm{d} s\right)^{\frac{1}{p}}}{\left[1-\left[a^{p}+c^{2}\right]^{p} \int_{0}^{t}\left(p^{2} k(s)-2 p\right) \exp \left(2 p \int_{0}^{s} Q_{1}(r) \mathrm{d} r\right) \mathrm{d} s\right]^{\frac{1}{p}}}
$$

Also

$$
Q_{1}(t)=\frac{\left[a^{p^{2}}+c^{2 p}+c\right] \mathrm{e}^{t}}{\left[1-p^{2}(2 p-1)\left[a^{p^{2}}+c^{2 p}+c\right]^{2 p-1} \int_{0}^{y} k(s) \mathrm{e}^{(2 p-1)} \mathrm{d} s\right]^{\frac{1}{2 p-1}}}
$$

Proof: Integrating both sides of (2.35) from 0 to $t$, and using (2.36), we observe that

$$
\dot{x}(t)=a+\int_{0}^{t} \dot{x}(s) f\left(s, \dot{x}^{p}(s), x^{2}(s)\right) \mathrm{d} s
$$

Taking absolute values of both sides of the above equation and using (2.37), we get

$$
|\dot{x}(t)| \leq a+\int_{0}^{t} k(s)|\dot{x}(s)|\left[\left|\dot{x}^{p}(s)\right|+x^{2}(s)\right] \mathrm{d} s
$$

The remaining proof is the same as Theorem 2.1 by following the same steps from (2.7)-(2.35) in (2.39) with suitable modifications, we get the required bound of (2.35).

We note that many generalizations, extensions, variants and applications of the inequality given in this paper are possible and we hope that the result given here will assure greater importance in near future.

\section{References}

[1] Ragab, A.A. (2000) On Integral Inequalities and Their Applications. Kyungpook Mathematical Journal, 40, 357-370.

[2] Pachpatte, B.G. (2001) On Some Fundamental Integral Inequalities and Their Discrete Analogues. Journal of Inequalities in Pure and Applied Mathematics, 2, 1-13.

[3] Pachpatte, B.G. (1977) On Some Fundamental Integrodifferential and Integral Inequalities. Analele. Stiintifice ale. Universitati.Al.I.Cuza.din.Iasi, 33, 77-86.

[4] Pachpatte, B.G. (1973) A Note on Gronwall-Bellman Inequalities. Journal of Mathematical Analysis and Applications, 44, 758-762.

[5] Pachpatte, B.G. (1975) On Some Integral Inequalities Similar to Bellman-Bihari Inequality. Journal of Mathematical Analysis and Applications, 49, 794-802.

[6] Pachpatte, B.G. (1974) An Integral Inequality Similar to Bellman-Bihari Inequality. Bulletin of the Greek Mathematical Society, 15, 7-12.

[7] Pachpatte, B.G. (1977) A Note on Gronwall Type Integral and Integrodifferential Inequalities. Tamkang Journal of Mathematics, 8, 53-59.

[8] Ullrich, D.F. (1969) Boundary Value Problems for a Class of Nonlinear Second Order Differential Equations. Journal of Mathematical Analysis and Applications, 28, 188-210.

[9] Beckenbach, E.F. and Bellman, R. (1961) Inequalities. Springer-Verlag, Berlin Heidelberg. http://dx.doi.org/10.1007/978-3-642-64971-4

[10] Meng, F.M. and Li, W.N. (2004) On Some Integral Inequalities and Their Applications. Applied Mathematics and Computation, 148, 381-392.

[11] Hooker, J.W. (1969) Existence and Oscillations Theorems for a Class of Nonlinear Second Order Differential Equations. Journal of Differential Equations, 5, 283-306.

[12] Ma, Q.H. and Debnath, L. (2003) A More Generalized Gronwall-Like Integral Inequality with Applications. International Journal of Mathematics and Mathematical Sciences, No. 15, 927-934. 
Scientific Research Publishing (SCIRP) is one of the largest Open Access journal publishers. It is currently publishing more than 200 open access, online, peer-reviewed journals covering a wide range of academic disciplines. SCIRP serves the worldwide academic communities and contributes to the progress and application of science with its publication.

Other selected journals from SCIRP are listed as below. Submit your manuscript to us via either submit@scirp.org or Online Submission Portal.
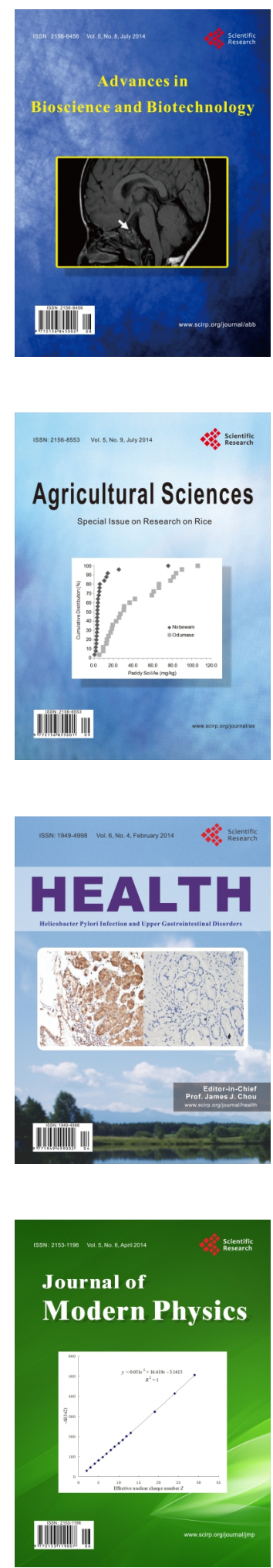
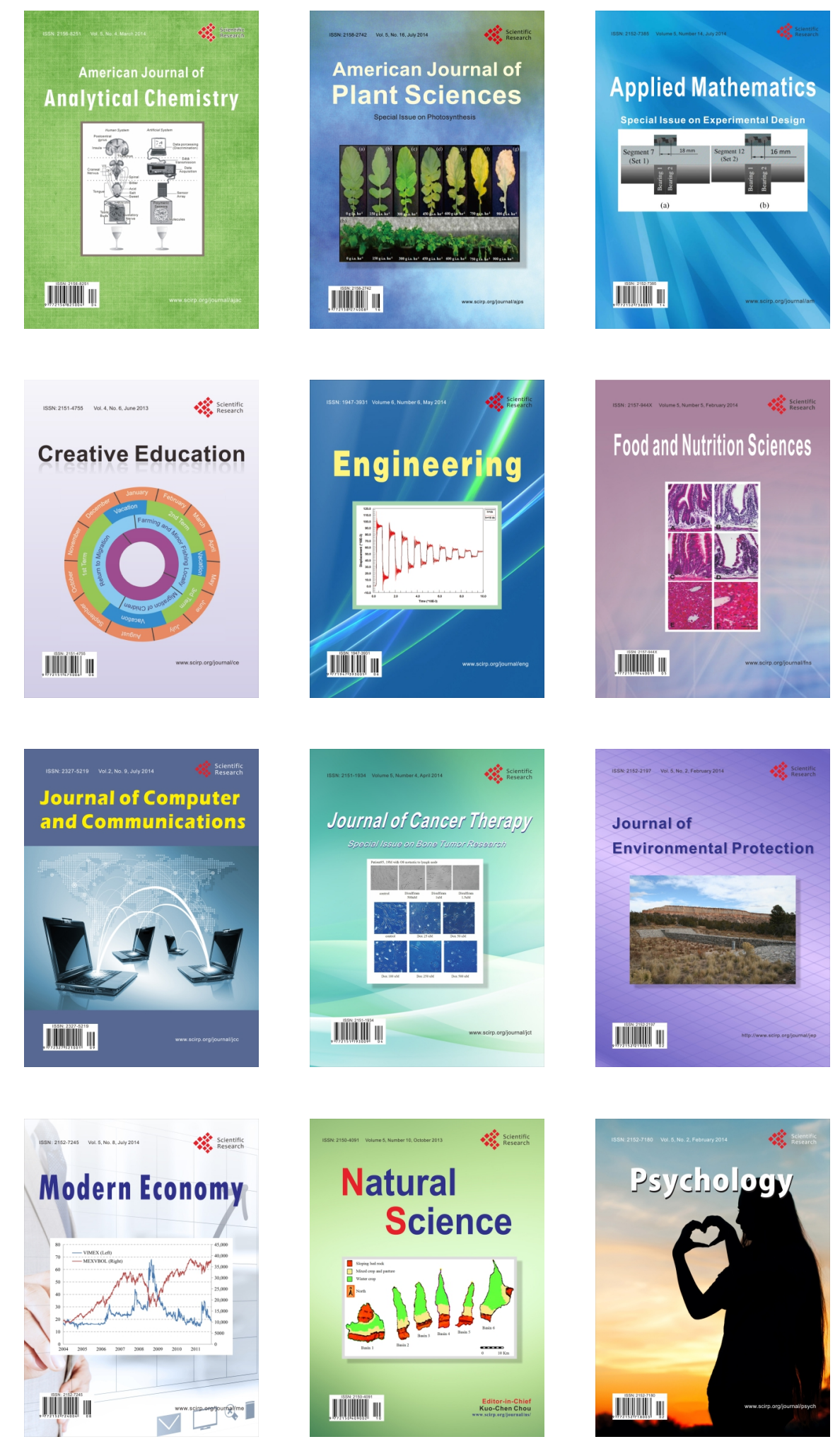